\title{
SELECCION DE PONENCIAS DEL XXVIII CONGRESO \\ DEL PSOE, CELEBRADO EN MADRID \\ DEL 17 AL 20 DE MAYO DE 1979
}

\section{PONENCIA POLITICA}

\section{PREAMBULO}

Al cumplirse los cien años de su fundación, el PSOE, en su XXVIII Congreso y basándose en su limpia trayectoria de lucha por la emancipación de los trabajadores, que asume plenamente con sus aciertos y errores, reafirma su Declaración Fundacional de Principios, como texto fundamental de su pensamiento y los desarrollos posteriores elaborados en sus congresos.

\section{Considerando:}

\section{PROGRAMA MAXIMO}

Que esta sociedad es injusta porque divide a sus miembros en dos clases desiguales y antagónicas: una, la burguesía, que, poseyendo los instrumentos del trabajo, es la clase dominante; otra, el proletariado, que, no poseyendo más que su fuerza vital, es la clase dominada.

Que la sujeción económica del proletariado es la causa primera de la esclavitud en todas sus formas: la miseria social, el envilecimiento intelectual y la dependencia política.

Que los privilegios de la burguesía están garantizados por el poder público, del cual se valen para dominar el proletariado.

Por otra parte:

Considerando que la necesidad, la razón y la justicia exigen que la desigualdad y el antagonismo entre una y otra clase desaparezcan, reformando o destruyendo el estado actual que las produce.

Que esto no puede conseguirse sino de un modo: transformando la propiedad individual o corporativa de los instrumentos del trabajo en propiedad común de la sociedad entera.

Que la poderosa palanca con que el proletariado ha de destruir los obstáculos que a la transformación de la sociedad se oponga ha de ser el poder público, del cual se vale la burguesía para impedir la reivindicación de nuestros derechos.

Por todas estas razones, el Partido Socialista declara que tiene por 


\section{Aspiración}

1. La posesión del poder político por la clase trabajadora.

2. La transformación de la propiedad individual o corporativa de los instrumentos de trabajo en propiedad común social o colectiva de la nación.

3. La constitución de la sociedad sobre la base de la Federación económica de la organización científica del trabajo y de la enseñanza integral para todos los individuos de uno u otro sexo.

En suma: el ideal del Partido Socialista es la completa emancipación de la clase trabajadora, es decir, la abolición de todas las clases sociales y su conversión en una sola de trabajadores, dueños del fruto de su trabajo, libres, iguales, honrados e inteligentes.

\section{PRINCIPIOS}

El PSOE tiene un texto fundamental, su Programa Máximo, que por seguir totalmente vigente constituye la base de todo nuestro pensamiento y acción, y debe ser el elemento esencial en la divulgación de lo que es nuestro Partido. Pero parece conveniente, para facilitar precisamente dicha divulgación, el concretar ideas de dicho texto en una serie de explicaciones claras y accesibles.

El PSOE se define como socialista porque su programa y su acción van encaminados a la superación del modo de producción capitalista, mediante-la toma del poder político y económico, y la socialización de los medios de producción, distribución y cambio por la clase trabajadora. Entendemos el socialismo como un fin y como el proceso que conduce a dicho fin, y nuestro ideario nos lleva a rechazar cualquier camino de acomodación al capitalismo o su simple reforma.

Declaramos que la sociedad socialista que preconizamos tendrá que ser autogestionaria. Las nacionalizaciones y la planificación no suponen necesariamente el socialismo. Queremos construir un modelo de sociedad que nos sea propio, en el que el socialismo y la libertad sean principios coadyuvantes y no contradictorios, en el que todos los hombres sean dueños de su trabajo y su conciencia, en el que el poder de decisión y los beneficios sociales pertenezcan solidariamente a la comunidad, y no a minorías dominantes, cualquiera que sea su signo. Para evitar la degeneración burocrática se exige levantar una democracia socialista, democracia en los partidos y en los sindicatos, en todos los órganos de poder y decisión que han de ser elegibles y revocables. Se exige la más amplia libertad de creación y crítica. En resumidas cuentas, el control y la autogestión de los trabajadores en todos los terrenos.

El PSOE reafirma su carácter de partido de clase, de masas, marxista, democrático y federal.

Somos un partido de clase, en cuanto defendemos y luchamos por el proyecto histórico de la clase obrera; la desaparición de la explotación del hombre por el hombre y la construcción de una sociedad sin clases.

Somos un partido marxista, porque entendemos el método científico de conocimiento y de transformación de la sociedad capitalista a través de la lucha de clases como motor de la historia. Entendemos el marxismo como método no dogmátíco, que se desarrolla y que nada tiene que ver con la traslación automática de los esquemas teóricos o prácticos de las experiencias determinadas del movimiento obrero. Aceptamos críticamente las aportaciones de todos los pensadores del socialismo y las distintas experiencias históricas de la lucha de clases.

Nos definimos como partido democrático al estar conformados como una or- 
ganización con la más escrupulosa democracia interna y de funcionamiento, a semejanza de la sociedad nueva que queremos construir, cuya mayor garantía está en la estructura democrática de las organizaciones que luchan por ella.

1. E1 PSOE propugna un método dialéctico de transición al socialismo que combine la lucha parlamentaria con la movilización popular en todas sus formas, que busque la profundización del concepto de democracia mediante la superación del carácter necesario pero no suficiente que las libertades políticas tienen en el estado capitalista y el acceso a las libertades reales; que señalen las reivindicaciones de cada momento, así como las alianzas que fueran precisas, en la perspectiva de que no puede existir libertad sin socialismo ni socialismo sin libertad; hasta que se llegue a una sociedad socialista, aún sin definir, existirá una etapa transitoria de construcción del socialismo en la que serán necesarias intervenciones enérgicas y decisivas sobre los derechos adquiridos y las estructuras económicas de la sociedad burguesa para conseguir la aplicación real de la democracia, y no su abolición.

2. El PSOE es un partido internacionalista y antiimperialista que concibe que la liberación de los trabajadores será efectiva cuando se realice a escala universal, y lucha por esta emancipación mundial; el PSOE se mostrará siempre solidario con la lucha de liberación de los pueblos oprimidos por el imperialismo económico o político de otras potencias.

3. La finalidad liberadora y desalienante del socialismo en su concepción de la sociedad sin clases y de garantía de la libertad real del hombre, hace que para el PSOE sea principio esencial de su doctrina la lucha por la conquista del poder político, como palanca para la construcción del socialismo y la utilización del Estado al servicio. de las libertades reales, de su defensa y protección y de su desarrollo más auténtico. Cada libertad conquistada históricamente es un hito en la lucha de clases y sirve de indudable apoyo en la siguiente conquista, debiendo ser defendida sin otra limitación que la que se derive de la prioridad de las necesidades sociales y solidarias sobre las individuales o egoístas.

4. E1 PSOE considera que la lucha por las libertades colectivas de las nacionalidades y los pueblos pasa por la impulsión de la configuración federal del Estado español. El PSOE ha de hacer que la clase trabajadora figure a la cabeza en la lucha por la autonomía de las nacionalidades y regiones oprimidas por una burguesía centralișta y retrógrada, teniendo en mente que sólo desde una perspectiva de clase se pueden vincular estas aspiraciones con una estrategia dinámica de solidaridad entre los intereses comunes a todas las nacionalidades y pueblos del Estado español.

\section{ANALISIS DE LA SITUACION POLITICA}

1. El PSOE considera que con la promulgación de la Constitución y las convocatorias de elecciones generales y municipales se ha dado un paso fundamental para conseguir el objetivo estratégico que se marcó en su XXVII Congreso: el restablecimiento de las libertades democráticas.

Entiende, sin embargo, que la RUPTURA DEMOCRATICA, como fue denominado en el XXVII Congreso el proceso por el cual se alcanzaba ese objetivo estratégico, no se ha agotado en su totalidad, al persistir en el aparato del Estado importantes sectores procedentes del antiguo régimen, cuyo cambio es imprescindible, puesto que en gran medida condiciona el inicio del período de consolidación de la democracia. Esta situación se debe a la forma adoptada por el proceso de ruptura.

2. La ley para la reforma política propició la separación del bloque de oposición al régimen franquista de los sectores de procedencia burguesa que, superando 
sus escrúpulos democráticos, se incorporaron al poder con el fin de contribuir al intento de controlar el cambio dentro del límite de sus respectivos intereses.

La estrategia combinada de la movilización de los trabajadores y la negociación con el poder desde las organizaciones democráticas de oposición forzó al Gobierno reformista a legalizar progresivamente a los sindicatos y partidos más representativos sin exclusión y a plantearse la necesidad de ir a una consulta democrática, que se concretizó en las elecciones del 15 de junio.

3. El objetivo propuesto por la derecha con las elecciones del 15 de junio era el de la legitimación del proceso reformista y de un régimen de monarquía constitucional de derechas, probando que el bloque popular carecía de los apoyos suficientes para llevar el proceso según sus planteamientos rupturistas.

Los resultados de las elecciones del 15 de junio de 1977, que demostraban al país que el pueblo depositaba un alto porcentaje de su confianza en la opción de la izquierda, y especialmente en el PSOE, supuesto la desarticulación de los planes de la derecha, cuya legitimidad se vería condicionada a seguir irreversiblemente el cambio institucional en profundidad que rompiera con la legalidad anterior.

4. Esta nueva relación de fuerzas, donde la posición de la izquierda era más equilibrada, aunque no hegemónica, obligó al Gobierno a enfrentar la elaboración de una Constitución negociando con los partidos de izquierda.

El PSOE entiende que de esta forma se consiguió el objetivo marcado por su XXVII Congreso de alcanzar un compromiso constitucional con todas las fuerzas políticas. El específico marco económico en el que se ha desarrollado la transición, la utilización masiva por la derecha de los aparatos del Estado, así como la necesidad prioritaria de dotar al país de un nuevo ordenamiento institucional, forzaron el denominado "consenso", en cuyo marco se han inscrito los Acuerdos de la Moncloa y la propia elaboración de la Constitución.

El PSOE considera que, si bien ha sido a través del proceso consensual como se han llegado a dar los pasos fundamentales para conseguir el objetivo prioritario y obtener las libertades democráticas, esto ha supuesto un elevado costo político: la desmovilización de los trabajadores que dificulta la relación del Partido con las masas, frenando su crecimiento y propiciando el deterioro de su actividad militante.

Costo político que, si no se tiene en cuenta luchando por la recuperación de la actividad y la participación de los trabajadores, puede impedir la consecución de la estabilización de la democracia en la perspectiva socialista.

5. Esta actitud explica nuestra corresponsabilidad en los Acuerdos de la Moncloa en la elaboración del texto constitucional. Pero no es una política previamente elegida. Es el punto de convergencia de dos condicionamientos elementales: el tipo de transición que vivimos y la relación de fuerzas, resultante de la confrontación electoral.

Aceptamos la negociación como una cierta renuncia, pero lo hicimos con plena conciencia de que con ello ayudaríamos al país a sortear los obstáculos de la transición a la democracia, aunque ello hiciera posible el mantenimiento en el poder de un confuso Gobierno de derechas durante el tiempo concertado que nos permitiera finalizar la tarea constituyente.

6. El PSOE considera que la Constitución de 1978, rompiendo la legalidad anterior, devuelve al pueblo su soberanía, respeta las legítimas aspiraciones autonómicas de las distintas nacionalidades y regiones, contempla los derechos y libertades de la persona y posibilita la remoción de los obstáculos que impidan o dificulten la libertad e igualdad de todos los individuos. Por tanto, el PSOE entiende que esta Constitución permite la estabilización de la democracia y supone un paso importante en el camino democrático al socialismo y, por consiguiente, la acata y está dispuesto a defenderla de cualquier intento involucionista que la amenace. 


\section{ESTRATEGIA}

1. Vía democrática hacia el socialismo y vía de acceso al Gobierno. Democracia y consolidación de la democracia.

La alternativa que el PSOE plantea para España tiene un doble carácter: de consolidación y profundización de la democracia, esto es, de eliminación de las restricciones a la libertad política y de ampliación de los márgenes de ejercicio de la misma. Y de ruptura con el capitalismo, o sea, de ordenación global del sistema sobre bases totalmente nuevas, mediante la puesta en práctica de una política de cambio social.

En la vía hacia la construcción de una sociedad socialista autogestionaria es preciso, como paso previo, la conquista del poder político por parte de los representantes de los diversos sectores y clases sociales interesados en un cambio de sociedad. El poder político sigue siendo el medio a través del cual las clases dominantes garantizan su predominio social. Es preciso, pues, conquistar el poder político para alterar definitivamente la relación de fuerzas sociales.

El PSOE, fiel a su tradición democrática y a la consideración de que el socialismo supone la implantación de la democracia a todos los niveles de la sociedad, se plantea la lucha por la conquista del poder político a través de la democracia. Sólo el socialismo garantiza la democracia; sólo la democracia puede garantizar la implantación del socialismo. El triunfo del socialismo depende de que se consiga sumar al ideal socialista y a la lucha por ese ideal a las más amplias mayorías de la población, y de que esas mayorías alcancen su voluntad mediante los recursos democráticos. En nuestra perspectiva, el fruto del socialismo no depende del hecho de que las denominadas «vanguardias» - los partidos revolucionarios, en el sentido leninista de la expresión- consigan vencer en un enfrentamiento frontal con las fuerzas representativas de los intereses dominantes. $\mathrm{Si}$ son los pueblos los que hacen la historia, el triunfo del socialismo dependerá de que los socialistas consigan con su acción permanente transformar a la mayoría de la población en partido político, hacer, esto es, que la mayoría de los ciudadanos que objetivamente están interesados en la construcción de una sociedad socialista se convierta en una mayoría política subjetivamente consciente y que luche decididamente, recurriendo al empleo de medios democráticos de expresión de su voluntad, por lograr una transformación de la relación de fuerzas, actualmente existente en las sociedades desarrolladas del mundo.

La profundización de la democracia, así pues, implica:

a) Una descentralización real del poder político. Una división real del poder político en diversos niveles: Estado, región, comarca, provincia, nacionalidad, municipio, barrio: respondiendo cada uno de ellos a los distintos niveles en los que se organiza la colectividad social y con competencias propias para resolver los problemas propios de dichas colectividades sociales.

$\mathrm{La}$ descentralización real del poder político no puede ser entendida sin una reforma fiscal en profundidad, mediante la cual se haga posible que cada uno de los entes político-sociales, a través de una adecuada distribución de los ingresos públicos, disponga de los medios necesarios para atender a las necesidades de la comunidad a la que representan.

b) Una democratización en profundidad de la vida política. Democratización que ha de ser entendida tanto a nivel institucional como a nivel popular.

A nivel institucional, mediante el recurso a procedimientos tales como la elección de todos los cargos, la reducción de la duración de los mandatos y la institu- 
cionalización de medios de consulta periódica a la voluntad popular (rendición de cuentas, referéndum, etc.).

A nivel popular, mediante la creación y potenciación de asociaciones y movimientos ciudadanos (asociaciones de vecinos, de consumidores, de usuarios, de servicios públicos, de defensa de la naturaleza, etc.), que sirvan de instrumento directo de participación y control de la gestión de los diversos entes políticos, de medio eficaz para la formación cívico-social y la elevación del nivel de conciencia de los ciudadanos, así como de cauce para la movilización de los más amplios sectores populares en defensa de sus legítimos intereses, posibilitando un salto cuantitativo de la clase trabajadora que haga realidad un proyecto cultural socialista.

La conquista progresiva de parcelas de poder político, esto es, la conquista por las fuerzas de la izquierda de los entes político-sociales intermedios (nacionalidades, regiones, provincias, municipios, etc.); siempre que estén dotados de un poder real (competencias, recursos financieros, etc.), permitirá no sólo una mejora de la relación política de fuerzas a nivel estatal, sino que, mediante la realización de una política progresista en esas colectividades, permitirá el ascenso en el nivel de conciencia y la mejoría relativa de condiciones de vida y trabajo de los sectores populares. $\mathrm{X}$ con ello incidirá favorablemente en una transformación de la relación social de fuerzas en beneficio de la clase trabajadora y demás sectores interesados en la construcción del socialismo.

La lucha democrática de los socialistas se mantiene, pues, después de haber avanzado un primer paso y ofrece cada vez más un abanico más amplio de posibilidades, una vez consolidadas las libertades. Hay que impulsar la democratización de las instituciones del Estado. El acceso de los trabajadores a los centros de poder pasa por la lucha por ampliar y profundizar la democracia. La victoria electoral y la política de Gobierno son necesarias para llegar al poder, pero para hacerlo posible es necesario el refuerzo constante de la participación del pueblo, de la presencia de la sociedad en el Estado. Hay que ampliar la democracia para hacer cada vez más grandes las áreas del poder social en manos de la decisión popular, sustrayéndolas a la apropiación privada; para extender cada vez más condiciones sociales suficientes para un igual ejercicio de la libertad. Hay que profundizar la democracia para generar nuevas formas de participación del pueblo en la dirección de la sociedad y del Estado, en la vía del socialismo y autogestión.

Esto exige una culminación de la actividad parlamentaria y de participación activa de los ciudadanos como elementos impulsores de una política de renovación. Las organizaciones populares, y en primer lugar la tarea del partido y del sindicato, son elementos básicos para el avance democrático. Esto implica un esfuerzo para mantener y ampliar la participación de los ciudadanos en el Estado y la política. Y significa también la adecuación progresivamente más íntima de las instituciones públicas, para que expresen y se apoyen en la voluntad democrática del pueblo. Es necesario estimular esta voluntad democrática para que sea posible avanzar en la consolidación dinámica de la democracia. $\mathrm{Y}$ a partir de ella progresar en el camino del socialismo.

2. Programa de cambio social: transformación de la estructura del Estado y reformas sociales.

La transformación de la sociedad española habrá de basarse en una política dirigida a la configuración de una nueva estructura del Estado español, mediante la cual se garanticen los más amplios márgenes para el ejercicio de las libertades individuales y colectivas y a la realización de una serie de reformas sociales que contribuyan al logro de mayores niveles de justicia y de igualdad social. En el camino de la ruptura del capitalismo, será precisa asimismo una política económica dirigida a superar la crisis económica sobre la base de conseguir el pleno empleo y una firme 
acción de Gobierno encaminada a aislar el terrorismo y a erradicar las causas de la delincuencia. Todas ellas son condiciones para conseguir la consolidación y profundización de la democracia española.

La nueva estructura del Estado español ha de basarse en la profundización de la configuración autonómica plasmada en la Constitución. La consecución de unos Estatutos de Autonomía que garanticen el mismo nivel de autogobierno para las distintas comunidades de España, hará posible una mayor democracia real en el sentido en que nos hemos expresado anteriormente.

Las comunidades autónomas no pueden suponer, sin embargo, ni la absorción ni el vacío funcional de los entes políticos menores - diputaciones y ayuntamientos-. Por el contrario, la plenitud del concepto de autogobierno se alcanzará en la medida en que las competencias autónomas descentralizadas sean gestionadas y ejecutadas descentralizadamente, a su vez, a través de dichos entes políticos territoriales menores. Con ello, por otra parte, se evitaría la creación de un aparato burocrático y funcionarial paralelo, que no haría sino encarecer los costes de la Administración pública.

El mantenimiento de las libertades logradas y la vigilancia contra los peligros de una marcha atrás es un deber permanente de los trabajadores y del pueblo, de los socialistas. La defensa del cumplimiento de la Constitución y el combate por el funcionamiento democrático de todas las instituciones públicas son el objetivo, en primer término, que desde la situación de primera fuerza de la oposición en España hemos de cumplir. La ampliación de la democtacia dentro del marco de la Constitución es el primer objetivo a alcanzar. Primer objetivo que exige no sólo una actuación dentro de las instituciones y la competencia electoral, sino también la creación de las condiciones sociales que lo hagan posible. Por tanto, impulsar la participación de los ciudadanos, la política de masas para la consolidación del marco democrático y hacer añicos los restos del franquismo son los objetivos actuales de los trabajadores.

La estrategia socialista, así pues, combina un contenido institucional y un contenido social. Una lucha en el interior de las instituciones del Estado para hacer más real y viva la democracia, y una lucha social para impulsar la participación del pueblo y su hegemonía en la sociedad civil. Los socialistas hemos de conseguir la hegemonía social de los trabajadores impulsando la vertebración de la sociedad civil. Por esto es necesario que los socialistas nos insertemos más y más en el tejido social. La posición de los socialistas, como el partido de los trabajadores más sólidamente implantado en el terreno electoral, nos obliga ahora a avanzar más en el camino de la vertebración social del pueblo, a ser una fuerza política presente en todas partes y expresiva de las reivindicaciones populares en el marco de un programa concreto de transformaciones, para que el apoyo electoral pueda ser transformado en una política de Gobierno socialista. Los socialistas hemos de sintetizar las diversas aspiraciones de cambio de cada uno de los sectores sociales dominantes, tanto en el programa como en la actuación, conectándolas con la actuación política dentro y fuera del Estado, poniendo siempre de relieve los intereses generales y políticos de los trabajadores e impulsando la unificación de las reivindicaciones anticapitalistas bajo un planteamiento general.

A través del impulso y apoyo de asociaciones culturales, deportivas, cooperativas, asociaciones de vecinos, etc., los socialistas hemos de estar profundamente insertos en el tejido social para recoger y potenciar las formas de vertebración popular para la defensa y expresión de intereses específicos o sectoriales, teniendo siempre presentes las formas más amplias, enraizadas y avanzadas de organización posible en las empresas y centros de trabajo, donde se encuentra la clase trabajadora y la mayor parte de su vida diaria. 


\section{POLITICA INTERNACIONAL}

El Partido Socialista Obrero Español, fiel a la tradición internacionalista y proletaria que presidió su creación por Pablo Iglesias en 1879 , se reafirma en el primer centenario de su creación como partido de trabajadores inserto en el Movimiento Obrero y Socialista Internacional y dedicado a la consecución de la paz y la coexistencia internacional entre todos los pueblos, manteniendo vivo el ideal del establecimiento de una sociedad socialista mundial. Para la consecución de estos objetivos, y dentro del marco de las resoluciones sobre la política del Partido en general, el PSOE considera esencial la realización de las siguientes tareas:

\section{Internacionalismo}

El Partido Socialista Obrero Español, miembro de la Internacional Socialista, fomentará la cooperación entre los pueblos para el logro de la paz y la igualdad entre los mismos.

A tal fin, el PSOE desarrollará sus relaciones con todos los partidos socialistas y progresistas del mundo, y apoyará cuantas iniciativas conduzcan a la emancipación de los trabajadores.

\section{Paz y seguridad internacionales}

El mantenimiento de la paz y de la seguridad internacionales ha de basarse en la estricta observancia y perfeccionamiento del actual sistema de Derecho internacional, en el tobustecimiento y democratización de la Organización de las Naciones Unidas y en el desarrollo del sistema de organizaciones intergubernamentales dependientes de la ONU, de conformidad con los principios de la Carta de la Naciones Unidas de 1945.

En especial, el Partido Socialista Obrero Español tratará de estimular el desarme internacional y se opondrá a la venta de material militar a aquellos regímenes políticos que pretendan imponerse por la fuerza, tanto en las relaciones internacionales como frente a sus propios pueblos. En consecuencia, exigirá un control democrático y efectivo del actual sistema de comercio exterior de armamentos.

\section{Derecho de los pueblos a la libre determinación}

El Partido Socialista reitera el derecho de los pueblos a la libre determinación, establecido en la Carta de las Naciones Unidas. Para la realización del mismo, los socialistas españoles ofrecen su ayuda a los pueblos colonizados o sometidos a procesos de explotación neocolonial.

El imperialismo, en todas sus formas, debe ser combatido, pues sólo una sociedad internacional basada en el principio de igualdad de derechos de los pueblos constituye una garantía de paz eficaz.

\section{Cooperación al desarrollo}

La división del mundo entre países explotadores y explotados es incompatible con el establecimiento de un sistema de paz.

En consecuencia, constituye tarea de los socialistas el cooperar al desarrollo de los pueblos económicamente oprimidos para acabar con toda situación de dependencia. Esta cooperación al desartollo ha de suponer transferencias de tecnología, capital y toda clase de recursos que permitan a los países en desarrollo adquirir su 
plena independencia política y económica dentro de un nuevo orden económico internacional.

El PSOE propondrá la participación de España a título de observador en las conferencias del Movimiento de Países no Alineados.

\section{Derechos del bombre}

La protección y garantía de los derechos humanos, sociales, políticos y culturales ha de proseguirse activamente tanto en la esfera universal como en la regional.

E1 Partido Socialista se preocupará especialmente por defender dichos derechos humanos en los países hermanos de la América Latina, ayudando a los movimientos democráticos y progresistas, condenando la tortura y otros tratos inhumanos, y exigiendo la liberación de los presos políticos.

El PSOE intervendrá en ayuda de todos aquellos refugiados políticos que llegasen a España provenientes de países donde regímenes dictatoriales o fascistas reprimen los derechos humanos.

\section{Relaciones con el mundo occidental}

E1 PSOE funda sus relaciones con los restantes países industrializados del mundo occidental en el principio de la igualdad de derecho y deberes, oponiéndose a cualquier pretensión hegemónica. En particular, se opone al ingreso de España en la OTAN o en cualquier otro pacto u organización militar, basada en la hegemonía, así como la concesión o utilización de nuevas bases o instalaciones militares a potencias extranjeras.

El Partido Socialista Obrero Español se esforzará por conseguir el desmantelamiento de las instalaciones militares extranjeras existentes en España, sin que en ningún caso ello comprometa la distensión o favorezca alguna de las grandes potencias.

La recuperación de la independencia y la integridad territorial de España incluye la definitiva descolonización de Gibraltar con reintegración a la comunidad española.

\section{Construcción europea}

El Partido Socialista Obrero Español desea una Europa unida, y para ello postulamos el fortalecimiento, desarrollo y democratización de las instituciones comunitarias.

El PSOE defiende la rápida integración de España en la Comunidad Europea, con las salvaguardias necesarias para el mantenimiento de la estabilidad económica y del empleo en España.

En la Europa comunitaria, las fuerzas socialistas, que constituyen hoy el principal grupo político, deberán actuar de modo unitario para la consecución de una sociedad socialista europea de los pueblos y de los trabajadores, poniendo coto a la expansión del capital multinacional y defendiendo los intereses de la clase obrera.

Durante la etapa de negociación del ingreso de España en la Comunidad, el PSOE defenderá los derechos de los trabajadores españoles en la Europa de los Nueve, pidiendo su equiparación con los trabajadores comunitarios.

E1 Partido Socialista exige la participación y audiencia de los partidos políticos y de las fuerzas sindicales españolas en las negociaciones de nuestra adhesión a las comunidades europeas.

De otra parte, el Consejo de Europa, al que España ya pertenece, debe conver- 
tirse en elemento dinámico para la integración política del Continente. Sus facultades deberán ser ampliadas en los sectores económico y social. España, en particular, deberá contribuir al mecanismo europeo de garantía de los derechos del hombre, mediante su aceptación del recurso individual a la Comisión y Tribunal Europeos de Derechos Humanos.

La Conferencia Europea de Seguridad y Cooperación, a celebrar en Madrid en 1980 , deberá ser aprovechada para reforzar los lazos entre todos los pueblos de Europa occidental y oriental, cuyas relaciones deberán basarse en los principios de distensión y en el desarrollo de la cooperación económica y cultural.

\section{Mediterráneo}

El PSOE, miembro de la Conferencia Socialista del Mediterráneo, fomentará la amistad y cooperación entre los pueblos de ambas orillas de este mar. Es necesario conseguir la retirada de este área de todas las fuerzas militares ajenas a los países del Mediterráneo.

Los conflictos deberán ser solucionados por medios pacíficos entre las naciones ribereñas, sin recurrir en ningún caso a la intervención de potencias ajenas.

La solución de la crisis del Oriente Medio habrá de basarse en el respeto a los derechos de los pueblos a la libre determinación y, en especial, al reconocimiento de los legítimos derechos del pueblo palestino, de conformidad con las resoluciones adoptadas por la Organización de las Naciones Unidas.

\section{Magreb}

Las relaciones con los países del norte de Africa han de basarse en la buena vecindad, el desarrollo de los intercambios y la cooperación.

Los socialistas españoles propugnan una urgente solución negociada al problema del Sahara occidental que permita el reconocimiento del derecho de autodeterminación del pueblo saharahui, como medio necesario para llegar a la pacificación de la región.

Es necesario establecer un amplio sistema de cooperación económica que haga posible la racional explotación de los recursos económicos terrestres y marítimos de la zona, en beneficio de nuestros pueblos y de nuestras clases trabajadoras.

En especial, consideramos urgente la conclusión de un amplio acuerdo de pesca con los legítimos representantes de los pueblos vecinos que garantice a los pescadores españoles el ejercicio de sus actividades en las zonas en las que venían haciéndolo de modo tradicional, con las limitaciones que imponen la protección de recursos biológicos.

\section{Africa}

Los socialistas españoles se esforzarán por una mayor colaboración entre España y los países africanos. Fomentando las relaciones políticas, económicas y culturales de todo tipo, especialmente con los regímenes progresistas del Continente.

Es esencial que los países industrializados contribuyan al desarrollo de los pueblos de Africa, mediante una ayuda masiva económica y técnica, a través del apoyo a sus economías en el comercio internacional.

Los socialistas españoles exigen la estricta aplicación de las resoluciones de las Naciones Unidas en la lucha por la autodeterminación y la igualdad, contra el imperialismo y el apartbeid en el sur de Africa, y se oponen al mantenimiento de relaciones comerciales en contravención con las resoluciones de la $\mathrm{ONU}$, especialmente en cuanto al suministro de armas de los regímenes racistas. 
El PSOE condena la tiranía que oprime al pueblo de Guinea Ecuatorial, antigua colonia española, y contribuirá a toda iniciativa que tienda a hacer posible el establecimiento de las libertades, la democracia y el respeto de los derechos humanos en dicho país.

\section{América Latina}

E1 PSOE mantendrá su política de colaboración con los partidos socialistas y progresistas de la América Latina, y se esforzará por mejorar e incrementar la cooperación económica entre España y los países de esa zona estimulando el desarrollo económico de los pueblos latinoamericanos.

Esta política requiere la creación de organismos eficaces de cooperación entre el PSOE y los partidos socialistas y progresistas de la América Latina, así como entre el Estado español y las actuales organizaciones políticas y económicas de la zona.

Para la consolidación de la paz y el desarrollo económico y social de la región es esencial luchar contra los regímenes dictatoriales, que se han convertido en instrumentos al servicio del imperialismo para la opresión de los pueblos latinoamericanos.

\section{PONENCIA DE ORGANIZACION Y ESTATUTOS}

\section{DISPOSICIONES GENERALES} pañol.

Art. 1. ${ }^{\circ}$ La denominación del Partido es la de Partido Socialista Obrero Es-

Art. 2. ${ }^{\circ}$ El Partido Socialista Obrero Español es una organización política de la clase trabajadora, que se configura como instrumento de ésta para la consecución de su completa emancipación a través de la transformación de la sociedad. Sus objetivos y programa son los fijados por su Declaración de Principios y las resoluciones de sus congresos.

Art. 3. $\mathrm{La}$ organización del Partido se inspira en los siguientes principios:

a) La democracia como forma de participación de los militantes en la vida del Partido.

b) El respeto a la libertad de conciencia, el libre pensamiento y a la libertad de expresión en el seno del Partido de cada uno de sus militantes. Se garantiza la total libertad de discusión interna, aunque no se permitirá la formación de tendencias organizadas. del Partido.

c) El cumplimiento de las decisiones adoptadas por los órganos competentes

d) La concepción federal de la organización, entendida como integración de las colectividades que la componen y basada en la autonomía de sus órganos dentro de las competencias que estatutariamente le corresponden.

Art. 4. Para pertenecer al Comité Federal, Comisión Ejecutiva Federal, Comisión Federal de Conflictos y Comisión Revisora de Cuentas será necesario haber pertenecido al Partido, ininterrumpidamente, durante los veinticuatro meses inmediatamente anteriores a la elección para tales cargos. 
Art. 5. La edad mínima para afiliarse al Partido es de dieciocho años. La solicitud de afiliación habrá de dirigirse al Comité Local del lugar de residencia del solicitante y habrá de ser avalada por dos miembros del Partido que tengan, como mínimo, un año de antigüedad en su permanencia en éste. La afiliación, acordada por un Comité, habrá de ser ratificada por la correspondiente asamblea en la primera sesión ordinaria que se celebre.

Las propuestas de alta se harán públicas en los tablones de los locales con quince días de antelación y se harán constar en el orden del día de la asamblea correspondiente.

Art. 6..$^{\circ}$ En caso de oposición motivada por un miembro de la agrupación local, la afiliación puede ser denegada previa audiencia del interesado por el Comité Local. Este adoptará, después de estudiar los informes presentados, la resolución que proceda. En caso de denegación de ingreso cabrá recurso, por los afiliados que lo avalen, ante la asamblea correspondiente en primera instancia, y en segunda ante la Comisión de Conflictos de la agrupación provincial, comarcal o insular.

Art. 7. En supuestos excepcionales, la Comisión Ejecutiva Federal podrá conceder el ingreso directamente. Las personas así afiliadas, que no pertenecerán a ninguna agrupación y dependerán en su actuación de la $\mathrm{CEF}$, no podrán ejercer el voto ni ostentar cargos orgánicos de representación del Partido.

Art. $8 .^{\circ} 1$. Serán derechos y deberes de todos los afiliados:

a) Participar activamente en la vida interna de la organización y ejercer el derecho de voto en todas las materias y casos en que corresponda.

b) Utilizar los servicios de la organización, reunirse en los locales de la misma y expresarse a través de sus órganos.

c) Ser elector y elegible para todos los cargos de la organización.

d) Recibir la solidaridad de la organización en caso de persecución por sus actividades en defensa de los ideales del Partido.

e) Representar al Partido en todas aquellas funciones o cargos para los que éste le designe.

f) Abonar puntualmente las cotizaciones y difundir las publicaciones de la organización.

g) Los afiliados al PSOE desarrollarán su militancia bajo la coordinación del correspondiente Comité Local, realizando actividades concretas al servicio de los objetivos programáticos del Partido.

2. Los miembros del Partido aceptan y están obligados a cumplir y defender la declaración de principios, programa, resoluciones y estatutos aprobados por sus congresos, así como las decisiones emanadas de sus órganos rectores, no pudiendo pertenecer a ninguna otra organización política, salvo lo dispuesto en el artículo para la emigración.

3. Todos los derechos y deberes que corresponden a los afiliados se ejercerán en la forma y con requisitos establecidos por los estatutos y las resoluciones complementarias emanadas de los órganos competentes.

4. Ningún miembro del Partido puede ser desposeído de los derechos que le corresponden sino en virtud de decisión adoptada por los órganos competentes, previo el procedimiento que se establezca para cada caso.

Art. 9. Los miembros del Partido, asalariados y trabajadores autónomos están obligados a actuar sindicalmente, solicitando el ingreso en la Unión General de 
Trabajadores. En su acción sindical deberán aplicar y defender la estrategia sindical del Partido, decidida por los órganos competentes del mismo en cada caso.

Art. 10. El afiliado que observe mala conducta cívica, falte al programa o a los acuerdos del Partido, haga declaraciones públicas que puedan deteriorar su imagen, haga traición a la solidaridad obrera en las luchas contra el capital, cometa actos notoriamente graves de indisciplina, lance calumnias contra algún afiliado, provoque conflictos graves entre los compañeros o de cualquier otra forma viole las obligaciones que a todos los miembros del Partido imponen los presentes Estatutos, será sancionado con medidas que podrán llegar hasta la expulsión, previos trámites reglamentarios y mediante decisión de los órganos competentes.

Art. 11. Será causa de baja automática en la organización el adeudar las cuotas de seis meses sin causa justificada. No se tomará en consideración una posterior solicitud de ingreso hasta tanto no hayan sido abonadas las cuotas pendientes de pago en el momento de causar baja.

Art. 12. Los afiliados del Partido tendrán derecho a intervenir en las deliberaciones de la agrupación de la localidad donde accidentalmente residan, sin derecho al voto, salvo acuerdo en contrario de los respectivos congresos de nacionalidad o regionalidad.

Art. 13. Los miembros del Partido no pueden prestar su apoyo o participación a manifestaciones, actos o cualquier otra iniciativa política promovida por otras organizaciones sin el consentimiento previo de los órganos ejecutivos competentes en cada caso según el carácter de tales actos.

TITULO II: DE LA ESTRUCTURA GENERAL DEL PARTIDO

Art. 14. E1 PSOE es una organización política de carácter federal, constituida y estructurada sobre la base de partidos o federaciones de nacionalidad o región, integrados por agrupaciones locales, comarcales o provinciales, o insulares en su caso.

Art. 15. Cada partido o federación de nacionalidad o región determinará su propio nombre, que deberá ir necesariamente acompañado de las siglas PSOE.

Art. 16. Cada partido o federación de nacionalidad o región tendrá plena autonomía para establecer el programa específico para su ámbito de competencia, así como para establecer su estructura interna dentro de los siguientes principios generales:

a) La unidad básica de militancia es la agrupación local. Su ámbito territorial es el municipio. Si las circunstancias lo aconsejan, en un mismo municipio podrán constituirse varias agrupaciones locales, de acuerdo con lo establecido en sus estatutos. Todos los afiliados deben pertener a la agrupación local que les corresponda según su lugar de residencia, salvo lo dispuesto en el artículo $7 .^{\circ}$.

b) Las agrupaciones locales serán responsables del cumplimiento de las obligaciones de los militantes, así como de procurar su participación en las tareas del Partido.

c) Los órganos de la agrupación local son la Asamblea y el Comité Local.

1. La Asamblea Local es el órgano soberano de la agrupación. Está compuesta por todos los afiliados.

2. El Comité Local es el órgano ejecutivo de la agrupación. Es elegido por la Asamblea y responde ante ella en asambleas ordinarias, que se convocarán especialmente para este fin cada cuatro meses. 
d) Las agrupaciones locales establecerán sus propios reglamentos de acuerdo con los Estatutos federales, nacionales o regionales y provinciales.

e) Las agrupaciones locales pueden constituirse agrupaciones comarcales, provinciales o insulares.

f) La misión de la agrupación comarcal, provincial o insular es desarrollar en su ámbito la política general del Partido, así como llevar a cabo las iniciativas necesarias para hacer frente a sus problemas, de acuerdo con las directrices generales de los órganos superiores.

Art. 17. La denominación, organización y estatutos de cada partido o federación regional o de nacionalidad tendrán que ser ratificados pos el Comité Federal en el plazo máximo de seis meses desde su presentación.

Art. 18. Todo miembro del PSOE que traslade su residencia desde el área de una agrupación a otra deberá solicitar su traslado a ésta, y se le reconocerá automáticamente si goza de todos sus derechos.

Art. 19. Son órganos del Partido o Federación nacional o regional, el Congreso regional o nacional, el Consejo regional o nacional y la Comisión Ejecutiva nacional o regional.

Art. 20. Cualquier actuación de los órganos de las colectividades que integran al Partido que resultase contraria a lo establecido en estos estatutos, a las resoluciones del Comité Federal o de la Comisión Ejecutiva Federal podrá ser suspendida y dejada sin efecto por decisión de la Comisión Ejecutiva Federal, remitiéndose la resolución definitiva a la primera reunión que se celebre del Comité Federal.

Igual competencia corresponderá a las comisiones ejecutivas nacionales o regionales respecto a las actuaciones realizadas en su ámbito.

Art. 21. Aquellos socialistas del Estado español que residan en el exterior podrán, sin perjuicio de su militancia en los partidos hermanos de la Internacional, previa autorización de la Comisión Ejecutiva, afiliarse al PSOE, constituyendo una agrupación en su lugar de residencia, siempre que sean en número superior a nueve militantes.

Las secciones del PSOE establecidas en el extranjero podrán formar una o varias federaciones de la nación en que residan, siempre que sean constituidas por un número de afiliados superior a 50 . En la nación que no lleguen a ese número serán integradas en la nación más próxima.

Si en un Continente los socialistas no pudieran llegar al número determinado, éstos, constituidos en secciones, podrán vincular directamente a la C. E. Federal del Partido.

\section{TITULO III: DE LOS ORGANOS FEDERALES DEL PARTIDO}

\section{Capítulo $10^{\circ}$ Del Congreso Federal}

Art. 22. El Congreso Federal del Partido es el órgano soberano del mismo.

Está constituido por las delegaciones de las agrupaciones provinciales, comarcales o insulares, compuestas por delegados elegidos en función de la estructura interna de la organización. El pleno de los delegados elegidos por cada agrupación provincial, comarcal o insular podrá decidir la composición de una sola delegación al Congreso por la federación de nacionalidad o región, garantizando en todo caso la libertad de los delegados de las respectivas agrupaciones provinciales, comarcales o insulares para mantener su propia delegación.

E1 número de delegados será fijado por el C.F. en proporción al número de afiliados al corriente de pago en el momento de convocar. El número de delegados no excederá en ningún caso de 1.000 . 
El Congreso se reúne ordinariamente cada dos años y extraordinariamente cuando lo convoque el Comité Federal o la Comisión Ejecutiva Federal, o lo solicite al menos la mitad más uno de sus afiliados. El Congreso Federal define los principios y fija los programas del Partido, establece la línea política del mismo y señala la estrategia de las luchas de clases entre Congreso y Congreso.

El Congreso Federal debate y juzga la gestión de la Comisión Ejecutiva Federal, del Comité Federal, de la Comisión Revisora de Cuentas y de la Comisión Federal, así como de los contenciosos que se le presenten en última instancia.

El Congreso elige a la Comisión Ejecutiva Federal, la Comisión Federal de Conflictos y la Comisión Federal Revisora de Cuentas.

Art. 23. Las decisiones del Congreso se adoptarán por aclamación, cuando el apoyo unánime es evidente; por tanteo, esto es, por mayoría de delegados que ostenten el voto de las degelaciones o por votación nominal, cuando 10 o más delegados lo soliciten o lo estime la presidencia, computándose entonces a efectos de escrutinios el número de mandatos acreditados por la Comisión de Credenciales.

El Congreso decide sobre su propio Reglamento de funcionamiento.

Art. 24. Las proposiciones al Congreso serán formuladas por los partidos y federaciones de nacionalidad o región, agrupaciones provinciales, comarcales o insulares elaboradas en forma de ponencias estructuradas por materias.

Art. 25. La elección por el Congreso de la Comisión Ejecutiva Federal, de la Comisión Federal de Revisión de Cuentas y de la Comisión Federal de Conflictos se realizará mediante votación secreta, previa presentación de los candidatos a la Comisión de candidaturas.

Art. 26. El Congreso Federal del Partido será convocado por el Comité Federal, quien determina las fechas y lugar de reunión por lo menos con cuatro meses de antelación.

Tres meses antes de reunirse el Congreso deberán remitirse a la Comisión Ejecutiva Federal las proposiciones, y un mes después la Comisión Ejecutiva enviará a todas las agrupaciones una Memoria donde se contengan ordenadas todas las proposiciones recibidas, junto con la Memoria de su gestión, de tal modo que los afiliados dispongan de sesenta días para valorar los referidos documentos.

Art. 27. Cuando circunstancias especiales aconsejen la convocatoria de un Congreso Federal extraordinario o cuando proceda para tratar sobre algún tema específico, no será preciso atender los plazos establecidos en el artículo anterior, aunque, en todo caso, habrá de convocarse con un mínimo de cuarenta días de antelación.

El Congreso Federal extraordinario podrá ser convocado por el Comité Federal o la Comisión Ejecutiva y, preceptivamente, cuando lo pidan la mitad más uno de los afiliados; el órgano convocante determinará la fecha y lugar de su reunión, así como los puntos del orden del día.

El Congreso Federal extraordinario sólo puede adoptar resoluciones sobre las materias previstas en el orden del día para el cual fue convocado.

\section{Capítulo 2.० Del Comité Federal}

Art. 28. El Comité Federal es el máximo órgano del Partido entre Congreso y Congreso.

El Comité Federal está constituido por:

a) La Comisión Ejecutiva Federal.

b) Los secretarios generales de los partidos o federaciones de nacionalidad o región. 
c) Un representante de las JJ.SS.

d) La representación elegida de los partidos y federaciones de nacionalidad o región o, en su defecto, agrupaciones provinciales y de la emigración, de acuerdo con los siguientes criterios:

- Cuatro representantes de cada partido o federación de nacionalidad o región que comprenda tres o más provincias, más un representante adicional por cada 3.000 afiliados o fracción.

- Dos representantes de cada partido o federación de nacionalidad o región que comprenda menos de tres provincias, más un representante adicional por cada 3.000 afiliados o fracción.

- Un representante por cada federación de la emigración.

- Un representante por cada federación provincial que no forme parte de ninguna federación de nacionalidad o región, más un representante adicional por cada 3.000 afiliados o fracción.

En todo caso, cada partido de nacionalidad o región tendrá un número de representantes no inferior al número de provincias que la integren.

Esta escala de representación permanecerá invariable hasta el próximo Congreso Federal. Cada miembro del Comité Federal será revocable en todo momento por.la instancia que lo eligió.

Los miembros del grupo parlamentario no podrán ser miembros electos del Comité Federal.

Los miembros del Comité Federal están obligados a informar puntualmente, de acuerdo con lo que determinen los estatutos de la organización que representa, a los órganos de dirección política de dicha organización. Del mismo modo podrán ser llamados a informar ante el Congreso o Asamblea Provincial por el Comité correspondiente.

Art. 29. Es competencia del Comité Federal:

a) Ratificar los estatutos de los partidos o federaciones regionales o nacionales $\mathrm{y}$ de las provincias.

b) Definir la política del Partido entre Congreso y Congreso.

c) Examinar la gestión de la Comisión Ejecutiva y aprobarla o rechazarla.

d) Establecer las líneas fundamentales de la política electoral del Partido, así como ratificar las listas electorales que le sean presentadas.

e) Examinar los informes de la Comisión Revisora de Cuentas y, en su caso, de la Comisión Federal de Conflictos, y entender en las cuestiones disciplinarias que le asignen los estatutos.

f) Designar y separar al director (y al administrador) de El Socialista, órgano oficial del Partido, a propuesta de la Comisión Ejecutiva Federal.

g) Elaborar su propio reglamento de funcionamiento, así como el reglamento de procedimiento en materia de conflictos.

b) Cubrir las vacantes que se produzcan en la Comisión Ejecutiva Federal, Comisión Federal de Conflictos y Comisión Revisora de Cuentas. Cuando las vacantes de la Comisión Ejecutiva Federal afecten a la Primera Secretaría o a la mitad más uno de sus miembros, el Comité Federal debe convocar Congreso extraordinario para la elección de una nueva Comisión Ejecutiva Federal.

i) Dar cuenta de su gestión y responsabilizarse de ella ante el Congreso $\mathrm{Fe}$ deral. A estos efectos, antes de cada Congreso, el Comité Federal elegirá una delegación de tres de sus miembros que no lo sean por razón de su cargo, encargados de presentar y defender la gestión del mismo ante el Congreso. 
Art. 30. El Comité Federal se reúne al menos cada cuatro meses, siendo convocado por la Comisión Ejecutiva Federal.

El Comité Federal puede ser convocado con carácter extraordinario cuando lo juzgue conveniente la Comisión Ejecutiva o lo soliciten al menos un tercio de sus componentes.

Las sesiones ordinarias deberán ser convocadas con, al menos, veinte días naturales de antelación. Las sesiones extraordinarias serán convocadas con la urgencia que requiera el caso y los acuerdos recaídos serán válidos, siempre que hayan sido notificados de la convocatoria todos sus miembros y se dé el quórum mínimo de dos tercios de sus componentes.

Cuando se produzcan vacantes entre los miembros del C.F., se procederá a una nueva elección por las asambleas, congresos o comités nacionales o regionales respectivos.

\section{Capitulo 3.० De la Comisión Ejecutiva Federal}

Art. 31. La C. E. realiza en el ámbito del Estado la política definida por los órganos de dirección del Partido, el Congreso Federal y el Comité Federal, adoptando para ello cuantas resoluciones considere necesarias, siempre de acuerdo con las normas directrices emanadas de aquéllos.

Art. 32. La C.F. aplica permanentemente la política del Partido; más específicamente es competencia de la C. E.: las relaciones internacionales y la organización de una red internacional de representaciones, las relaciones con ottos grupos políticos a nivel del Estado, la administración de los bienes del Partido y la realización de cuantas actividades sean necesarias en todos los aspectos para el cumplimiento de los fines del Partido al nivel del Estado.

Art. 33. La C. E. se reúne con la frecuencia que por sí misma acuerde. Normalmente será convocada por el secretario general; en su ausencia, por el vicepresidente general $y$, en su defecto, puede ser convocada mediante escrito de la mitad más uno de sus miembros. Las decisiones en la Comisión Ejecutiva se adoptan por mayoría simple de miembros presentes. Para que las decisiones adoptadas sean válidas se requiere que todos los miembros hayan sido notificados de la reunión y el quórum de mayoría simple. La C.F. podrá constituir dentro de su seno comisiones para asuntos específicos en los que delegue facultad de decisiones sobre los mismos. A tal efecto establecerá las normas reglamentarias que estime conveniente.

Art. 34. La Comisión Ejecutiva Federal es elegida en el Congreso, y estará compuesta por:

- Presidencia.

- Secretaría General Federal.

- Vicesecretaría General.

- Secretaría Federal de Organización.

- Secretaría Federal de Administración.

- Secretaría Federal de Formación.

- Secretaría Federal de Estudios y Programas.

- Secretaría Federal de Política Sectorial.

- Secretaría Federal de Prensa y Propaganda.

- Secretaría Federal de Política Municipal.

- Secretaría Federal de Relaciones Políticas.

- Secretaría Federal de Relaciones con las Juventudes.

- Secretaría Federal de Política Autonómica.

- Secretaría Federal de Política Sindical.

- Secretaría Federal de Emigración.

- Secretaría Federal de Cultura. 
Ocho vocalías federales, una de las cuales actuará como interventor. En circunstancias especiales podrá nombrarse un presidente de honor, que tendrá competencia para representar al Partido por delegación de la Comisión Ejecutiva Federal y que podrá participar en las tareas de ésta. Los secretarios se agruparán por áreas diferenciadas de actividad, a saber:

a) Política y estrategia, coordinada por el secretario general federal, que englobará la Secretaría General, Vicesecretaría General, Sindical Sectorial, Autonómica, Estudios y Programa.

b) Imagen: que englobará Prensa e Información y Propaganda e imagen.

c) Orgánico-administrativa: que englobará Organización, Administración, Formación y Municipal.

La C. E. F. elaborará un reglamento de funcionamiento interno que comunicará al Comité Federal para su conocimiento, en el que se indicarán las funciones propias de cada secretaría y vocales.

Art. 35. E1 presidente preside los actos oficiales del Partido y firma con el secretario general todos los documentos políticos.

El secretario general es el portavoz cualificado de la Comisión Ejecutiva. Ostenta la representación del Partido, coordina los trabajos de la Comisión Ejecutiva Federal y modera sus reuniones. La responsabilidad de la Comisión Ejecutiva es colegiada, lo que no exime a sus miembros de responsabilidad en el desempeño de sus funciones.

Las deliberaciones de la Comisión Ejecutiva son reservadas. Se hará constar en el acta de cada reunión los votos particulares que hubiere sobre las decisiones recaídas.

Art. 36. Las vacantes de la Comisión Ejecutiva Federal serán cubiertas por elección en el Comité Federal.

Art. 37. La Comisión Ejecutiva Federal editará los carnets y sellos que corresponda para todo el Partido. Dará de baja a las colectividades que adeuden más de seis meses de cotización.

Art. 38. La Comisión Ejecutiva Federal podrá dotar de equipos de asesoramiento técnico, cuyos miembros y las funciones que realicen pondrían en conocimiento del Comité Federal.

Art. 39. Los miembros de la Comisión Ejecutiva Federal que ocupen secretarías del área orgánico-administrativa no podrán ocupar cargos públicos, salvo en el caso de los inherentes a la función parlamentaria.

\section{Capítulo 4. De lo contencioso}

Art. 40. El Congreso Federal del Partido elije en cada una de sus reuniones ordinarias una Comisión Federal de Conflictos integrada por cinco miembros, que habrán de pertenecer necesariamente a distintas federaciones de nacionalidad o regionalidad. Esta comisión resolverá los expedientes instruidos con arreglo a las normas estatutarias y al reglamento de procedimiento que con este fin elabore el Comité Federal del Partido.

En todo caso, las decisiones de la Comisión Federal de Conflictos sólo son recurribles ante el Congreso Federal del Partido.

Ser miembro de la Comisión de Conflictos, a cualquier nivel, es incompatible con los siguientes cargos:

a) Miembro del grupo parlamentario.

b) Miembro de comités o comisiones ejecutivas del Partido, a cualquier nivel. 
c) Desempeñar cargos públicos en representación del Partido.

d) Ser funcionario al servicio del Partido, a cualquier nivel.

e) Pertenecer a comisiones revisoras de cuentas en cualquier órgano del Partido.

Art. 41. A nivel de nacionalidad o regionalidad existirá, asimismo, una Comisión de Conflictos elegida en el Congreso respectivo. Las resoluciones de aquélla serán recurribles en alzada en el plazo de treinta días ante la Comisión Federal. Contra las resoluciones de esta instancia cabrá recurso ante el Congreso Federal del Partido.

Art. 42. En los supuestos fijados en el artículo 10 de estos Estatutos, el Comité de la agrupación local a la que pertenezca el afiliado procederá a incoar el correspondiente expediente con audiencia del interesado, que será resuelto por la Comisión de Conflictos a nivel de nacionalidad o regionalidad o, en su defecto, provincial en el plazo de un mes, a partir de la recepción de las actuaciones producidas por el Comité de la agrupación. La resolución dictada será recurrible ante la Comisión Federal de Conflictos y, en última instancia, ante el Congreso Federal del Partido.

Las comisiones de conflictos, a los distintos niveles de su ámbito jurisdiccional, podrán suspender provisionalmente de militancia a cualquier afiliado que les sea remitido, siempre y cuando en la solicitud de apertura de expediente así lo solicitase el Comité Ejecutivo del correspondiente nivel y pueda argumentarse la necesidad de adoptar esta medida para evitar daños a la organización.

Su resolución no será objeto de recurso alguno.

En el plazo máximo de un mes deberá haber resuelto el expediente definitivamente.

Los comités locales, comarcales y provinciales, y las comisiones ejecutivas de nacionalidad o región federal serán meros ejecutores de las decisiones tomadas por la Comisión de Conflictos correspondiente, sin que puedan imponer a ningún afiliado o grupo de ellos sanciones que supongan la suspensión, exclusión o expulsión sin previa resolución de la Comisión de Conflictos.

\section{Capitulo 5.० De la Comisión Revisora de Cuentas}

Art. 43. La Comisión Federal de Revisión de Cuentas es el órgano encargado de supervisar la contabilidad y verificar la administración de los medios económicos del Partido, y controlar que su uso se adecúe a las resoluciones de los órganos directivos.

El juicio sobre la gestión económica y política de los bienes y derechos del Partido corresponde al Congreso Federal y, subsidiariamente, al Comité Federal. La naturaleza fidedigna de los informes y cifras que presenta la Comisión Ejecutiva Federal queda garantizada por la Comisión Revisora de Cuentas.

El Congreso Federal elige a la Comisión Federal de Revisión de Cuentas. Esta estará constituida por cinco miembros, cuya misión será la revisión semestral de las cuentas de la tesorería del Partido. Esta comisión responde únicamente al Congreso, si bien habrá de elevar un informe al Comité Federal cada vez que éste así lo solicite.

\section{TITULO IV: DE LOS GRUPOS SINDICALES}

Art. 44. Los militantes del Partido pertenecientes a la UGT, de acuerdo con el artículo 9. ${ }^{\circ}$, formarán grupos sindicales socialistas constituidos en los centros de 
trabajo y articulado en los distintos sindicatos conforme a la estructura orgánica de la UGT.

Art. 45. Los grupos sindicales no tendrán carácter orgánico y estarán coordinados por los secretarios (responsables o delegados) sindicales del Partido en cada nivel, teniendo como misión fundamental el desarrollar y aplicar la política sindical del Partido decidida por los órganos competentes.

\section{TITULO V: DE LOS PROCEDIMIENTOS ELECTORALES}

Art. 46. 1. Para la elaboración de listas de candidatos del PSOE a las elecciones legislativas, los comités provinciales o, en su caso, las comisiones ejecutivas de nacionalidad o región confeccionarán las listas basándose en las propuestas de las agrupaciones locales. Estas listas serán presentadas a la Asamblea Provincial o, en su caso, al Comité nacional o regional para la elaboración de la lista ordenada, que a través de los órganos de dirección respectivos será trasladada con el informe pertinente al Comité Federal.

En caso de que el Comité Federal, tras la consulta al órgano que generó la lista, decida introducir modificaciones en la misma, designará en su seno una comisión que deberá razonar con el informe correspondiente dichas modificaciones ante la instancia confeccionadora de la lista.

La decisión última corresponderá al Comité Federal o al órgano de dirección de nacionalidad o región en el que él delegue.

2. Cuando se trate de elecciones a asambleas de las comunidades autónomas y municipios de más de 10.000 habitantes enclavados en las mismas, los consejos (o comités) nacionales o regionales asumirán las competencias que el artículo anterior atribuye al Comité Federal. Este deberá ser informado de las listas aprobadas, y las ratificará o las devolverá al Consejo (o Comité) nacional o regional respectivo para su nueva elaboración, el cual seguirá el mismo proceso de razonamiento y explicación a la base que se describe en este artículo para el Comité Federal.

3. Para las candidaturas a municipios de menos de $\mathbf{1 0 . 0 0 0}$ habitantes, las respectivas asambleas locales elaborarán la lista, que será trasladada para su ratificación al respectivo Comité provincial, regional o de nacionalidad. Este informará al Comité Federal.

TITULO VI: DEL GRUPO PARLAMENTARIO DEL PSOE

Art. 47. El grupo parlamentario del PSOE está constituido por todos los can. didatos del PSOE que sean elegidos diputados y senadores.

Dentro del grupo parlamentario existirá el grupo socialista del Congreso y el grupo socialista del Senado.

Art. 48. Los miembros del grupo parlamentario del PSOE asumen y están obligados a acatar la declaración de principios, programa y resoluciones aprobadas en el Congreso Federal del Partido, así como las directrices emanadas de los órganos de dirección del Partido.

Art. 49. Todos los miembros del grupo parlamentario aceptan el compromiso de presentar su dimisión al presidente del Parlamento si, una vez elegidos, causasen baja en el PSOE por cualquier circunstancia.

Este compromiso se realizará por escrito dirigido al Comité Federal.

Art. 50. Los grupos socialistas del Congreso y del Senado elegirán de entre su seno a sus correspondientes presidentes y secretarios generales, así como los miembros de las respectivas secretarías que se estimen necesarios. 
Cada presidente será el portavoz del grupo socialista del Congreso y del Senado, respectivamente.

El presidente del grupo socialista del Congreso será el portavoz del grupo parlamentario. El Partido dotará al grupo parlamentario de los medios técnicos y humanos que sean precisos para el cumplimiento de sus funciones.

Art. 51. En todos los casos, los miembros del grupo parlamentario están sujetos a la unidad de actuación y disciplina de voto. Si no la respetasen, el grupo parlamentario y la Comisión Ejecutiva Federal podrán denunciar su conducta al Comité Federal. Si la actuación originada por el miembro del grupo se estimase grave por el Comité Federal, éste tendrá facultades para proceder a darle de baja del grupo parlamentario, procediendo a incoar el correspondiente expediente, que será tramitado a la Comisión Federal de Conflictos para que dicte las resoluciones a adoptar.

Art. 52. Las asignaciones económicas y emolumentos que perciban los miembros del grupo parlamentario se ingresarán automáticamente en la Secretaría Federal de Administración. El Comité Federal procederá a fijar las asignaciones económicas correspondientes del grupo.

Art. 53. A efectos orgánicos, los miembros del grupo parlamentario continuarán vinculados a sus unidades orgánicas, aun cuando sólo dependen del Comité Federal y, en su defecto, de la Comisión Ejecutiva Federal, respecto a su actividad en el Parlamento.

Art. 54. Aquellos parlamentatios que no estén afiliados al PSOE, pero que deseen inscribirse en el grupo parlamentario del PSOE, pueden hacerlo, siempre que acepten las obligaciones que figuran en los artículos 48 y 51 de estos reglamentos, previa propuesta del secretario general del grupo socialista de que se tratase, a la Comisión Ejecutiva Federal. En ningún caso podrán representar al grupo socialista respectivo.

\section{TITULO VII: DE LOS GRUPOS PARLAMENTARIOS DE NACIONALIDAD O REGION}

Art. 55. Los grupos parlamentarios de nacionalidad o región, para todas aquellas cuestiones específicas de su ámbito territorial, dependerán de los órganos de dirección correspondiente, debiendo asumir y acatar las resoluciones y programas en materia de política parlamentaria de los mismos.

\section{TITTULO VIII: DE LAS JUVENTUDES SOCIALISTAS}

Art. 56. Las JJ.SS. constituyen la organización juvenil del PSOE y, como tal, tanto sus órganos directores como sus militantes están obligados a aceptar y cumplir el programa y resoluciones del Congreso, acuerdos del Comité Federal y de la Comisión Ejecutiva.

Art. 57. Los militantes de las Juventudes Socialistas que están militando al mismo tiempo en el PSOE tienen todos los derechos y deberes que figuran en los estatutos.

Art. 58. Las JJ.SS, tendrán autonomía en sus organizaciones de base, concretada en la posibilidad de celebrar sus propios congresos y de elección de órganos de dirección a todos los niveles, si bien las resoluciones de las JJ.SS. tendrán que ser refrendadas por los órganos de dirección del PSOE, a fin de que no existan contradicciones.

Art. 59. Los militantes del PSOE menores de veinticinco años y que estén des- 
arrollando su labor política en el ámbito juvenil estarán obligados a militar en las Juventudes Socialistas.

Art. 60. Las JJ.SS., en coordinación con el PSOE, tendrán la tarea de la elaboración de la política socialista para la juventud trabajadora, la juventud estudiantil y la juventud en los barrios.

TITULO IX: DE «EL SOCIALISTA»

Art. 61. El Partido Socialista Obrero Español tiene como órgano de expresión El Socialista, teniendo que figurar en su cabecera: «Fundado por Pablo Iglesias.» Su periodicidad habrá de ser fijada por el Congreso Federal o, en su defecto, por el Comité Federal.

Art. 62. La dirección y administración de El Socialista es responsabilidad directa de la C. E. F. del Partido, si bien el director del mismo habrá de ser designado por el Comité Federal a propuesta de la Comisión Ejecutiva Federal.

\section{DISPOSICION ADICIONAL.}

La articulación orgánica de los partidos federales surgidos de procesos de unidad socialista se regulará por lo establecido en los respectivos acuerdos de unidad aprobados por el Congreso correspondiente.

\section{ADMINISTRACION}

1. El PSOE, como partido obrero y de clase, asegurará su financiación a todos los niveles con los ingresos por conceptos de cuotas de sus militantes, las subvenciones estatales previstas por la ley y cuantos ingresos procedan de las gestiones de los respectivos órganos rectores.

2. Se establece la cuota a la C.E. F. en 30 pesetas mensuales por militante.

3. Se recomienda el 1 por 100 del salario o ingreso mensual como cuota mínima del militante. No obstante, ésta deberá ser fijada por los respectivos congresos de nacionalidad o región, por las asambleas provinciales y/o comarcales (donde las hubiere) y por las locales en sus niveles respectivos. A criterio de las agrupaciones locales, quedarán exentos de pago de la cuota los militantes que se encuentren en situación económica precaria, sin perjuicio de abonar la cantidad que corresponda a la C. E. F. y la que pueda fijar el Comité Ejecutivo regional o de nacionalidad.

4. Los ingresos de las colectividades se canalizarán a través de los órganos políticos competentes determinados en los congresos regionales y de nacionalidades.

5. El cobro de cuotas y distribución de sellos lo realizará la C. E. F. a través de las comisiones ejecutivas de nacionalidad o región y, en su defecto, provincial, si así está estructurada; la nacionalidad o región, siempre y cuando lo determinen sus respectivos congresos de nacionalidad o regionalidad, detallando éstas los distintos conceptos y agrupaciones a que corresponda.

6. Se podrá suspender de los derechos políticos de voto, pero no de voz, a aquellos militantes que adeuden más de tres mensualidades.

7. Los presupuestos anuales generales del Partido deberán ser elaborados por la Comisión Ejecutiva Federal y presentados al Comité Federal para su aprobación, si procede, durante el último trimestre del año. 
8. Los presupuestos generales del Partido deberán cubrir los gastos ejecutivos y organizativos federales, así como la amortización de las deudas pendientes contraídas y el reforzamiento de la estructura federal.

9. Los ingresos anuales procedentes de la subvención estatal de ayuda a los partidos políticos se canalizará su distribución de la siguiente forma:

a) Un 25 por 100 para amortizar déficits de campañas electorales.

b) Un 30 por 100 para la creación de un fondo compensatorio de acción coyuntural que permita atender a nivel federal aquellas necesidades más perentorias y que estime oportunas la C. E.F.

c) Un 45 por 100 se destinará a dedicar especial atención a las regiones o nacionalidades donde no se ha implantado convenientemente el Partido.

10. La organización y gestión de las finanzas del PSOE y de todas las organizaciones políticas en él federadas se atendrán a criterios de publicidad, previsión y control presupuestario.

11. La publicidad sobre las previsiones de ingresos y gastos, elaboradas con detalle y tiempo suficiente para períodos fijos, alcanzará, como mínimo, a los conceptos correspondientes o similares a los que figuran en los Presupuestos Generales del Estado.

12. El Comité Federal del PSOE formará de entre sus miembros una comisión que, con el informe y el auxilio de los compañeros expertos en técnicas presupuestarias y planes de cuentas y financiación de organizaciones de masas, se ocupe de elaborar planes contables estandarizados para todas las organizaciones federadas, así como de lo relativo a su puesta en funcionamiento, gestión y control.

13. La distribución presupuestaria de ingresos y gastos, o los criterios para determinarla, deberá ser estudiada y debatida, al menos, en los respectivos congresos del PSOE o, en su caso, en los de las organizaciones federadas, en base a propuestas en documento público y normalizado. De entre las diversas técnicas y clasificaciones presupuestarias se usará aquélla o aquéllas que mejor informen sobre los aspectos críticos y que permitan un más fácil control democrático por parte de los afiliados y los ciudadanos.

14. Los presupuestos detallados de ingresos y gastos previstos y realizados de las agrupaciones se refundirán en un presupuesto integral de partido o federación provincial, de región o de nacionalidad, y éstos en un PRESUPUESTO GLOBAL UNICO FEDERAL DEL PSOE.

15. En todo caso, el proceso de racionalización de la administración, gestión y control de los medios económicos a nivel federal respetará la soberanía de las organizaciones o partidos integrados en la Organización Federal para gestionar sus propias finanzas.

16. Las comisiones revisoras de cuentas responderán de la veracidad, justificación documental o similar y pulcritud de las cuentas, presupuestos vencidos y proyectos de gastos que se presenten; los criterios económicos y políticos que deban informar o hayan informado la administración y gestión de ingresos y gastos.

17. La Comisión Revisora de Cuentas se reunirá cada tres meses, realizando la previsión del trimestre siguiente y la revisión del vencido.

18. E1 PSOE deberá buscar fórmulas que le aseguren su autofinanciación; para ello hay que reducir cuantos gastos se puedan a todos los niveles, poniendo en pie unos servicios que ahorren gastos y aseguren prestaciones de servicios.

Todo este planteamiento administrativo está elaborado en función de un mejor control y redistribución del movimiento económico, así como garantizar una mejor trasparencia de la gestión administrativa. 


\section{POLITICA DE DEFENSA Y POLITICA MILITAR}

Para abordar con un mínimo de coherencia el tema de la política militar (que trata de las Fuerzas Armadas) es preciso situarlo dentro de unos marcos mayores, que lo encuadran y engloban: la política de defensa que trata de la forma de defender el país y de la política internacional, de la que deriva la política de defensa.

\section{Política internacional: la defensa de la libertad y la soberanía}

Durante la presente etapa los socialistas consideramos que la política de defensa más conveniente es aquélla que garantice un máximo de libertad; para en el futuro avanzar hacia el socialismo con un mínimo de riesgo; y esta política implica la no alineación, por lo que ya en el XXVIII Congreso se decidió «adoptar progresivamente una política de neutralidad activa en cuanto contribuya a la causa del socialismo» y «marcar la independencia frente a los bloques militares».

Dado que España no pertenece a la OTAN, no parece necesario dar razones para no ingresar, ya que la carga de la prueba corresponde a aquellos partidos que quieren modificar la situación presente; sin embargo, a continuación van a citarse en forma escueta algunas razones por las que los socialistas nos oponemos al citado ingreso, las cuales son en general políticas, pero también a veces económicas o meramente militares. Estas razones son las siguientes:

1. La OTAN nació para hacer frente a las necesidades defensivas de Occidente, en un período de guerra fría que acabó en 1975 con la firma de los convenios de Helsinki. En efecto, fue creada poco después del golpe de Estado de Checoslovaquia y del muro de Berlín, en plena vigencia del estalinismo y un momento histórico muy distinto al actual. Y esto ya lo comprendió De Gaulle en 1966, cuando forzó la salida de Francia de la organización. No parece, pues, nada lógico que España vaya ahora, trece años después, a potenciar una política internacional trasnochada, basada en la existencia de bloques militares hostiles y antagónicos.

2. El ingreso en la OTAN implica, de hecho (por la existencia de tropas o bases extranjeras) y de derecho (por las condiciones y obligaciones derivadas de los pactos), una limitación o cesión de la actual soberanía e independencia, sin obtener, como sería en el caso del Mercado Común, contrapartida alguna por el citado ingreso. Es preciso no olvidar que, una vez decidida la entrada de España en la OTAN, resultaría difícil la salida.

3. España practica desde hace ya siglo y medio una política de neutralidad, que ha creado tradición en el pueblo que vio con satisfacción nuestra neutralidad en las dos guerras mundiales. En este sentido, nuestro caso es homologable a los de Suecia y Suiza, que, con nosotros, son los tres únicos países de Europa que han permanecido neutrales en las dos contiendas. En consecuencia, el ingreso en la política de alianzas se tendría que hacer forzando la voluntad de una parte importante del pueblo, lo que sería altamente desestabilizador, ya que en política internacional es necesario el mayor acuerdo posible.

4. España está situada en el extremo de Europa, y, por tanto, antes de ser atacada deberían serlo otros países de la OTAN. En consecuencia, el ingreso en la OTAN no aumenta nuestra seguridad, mientras que, por el contrario, nos pone en riesgo de ser objetivo de bombas atómicas del potencial agresor. En resumen, las alianzas militares sólo tienen lógica entre países que corran el mismo o parecido riesgo de ser atacados por terceros, y no creemos que éste sea el caso de España, situada al suroeste de Europa, respecto a otros países situados en la frontera de los dos bloques. 
5. El ingreso en la OTAN exigiría homologar la organización y el equipamiento de nuestras FUERZAS ARMADAS con la de los demás países de la OTAN, lo que significaría (quizá con la excepción de la Marina) unos cambios tan radicales (retiro de gran número de militares profesionales al tenerse que homologar las edades, etc.) que daría lugar a serios problemas dentro de las propias Fuerzas Armadas, lo que no parece aconsejable desde ningún punto de vista.

6. El coste de estas transformaciones parece elevado. Sólo la transformación de la infraestructura se evalúa en unos 1.000 millones de dólares anuales sobre el actual presupuesto, que se eleva ya a 302.000 millones de pesetas (incluidas las clases pasivas y la Guardia Civil), lo que equivale a más de un 20 por 100 del presupuesto, cuyo total es de 1.433 .000 millones (Boletín Oficial de las Cortes, núm. 30, de 14 de noviembre de 1977). Como es lógico, en la actual coyuntura económica elevar los gastos de defensa significaría agravar la inflación con las consiguientes consecuencias. $\mathrm{Y}$ esto sin haber computado otros gastos inherentes al ingreso, como son los derivados del acuerdo de los miembros de la OTAN de elevar su presupuesto de defensa en un 3 por 100 , lo que otra vez redundaría en el agravamiento de la crisis.

Desechada la opción OTAN, es preciso tratar del Pacto de Mutua Defensa con Estados Unidos, que fue renovado el 24 de enero de 1976 para un período de cinco años. Desde un punto de vista económico, es un tratado ruinoso, consecuencia del complejo de culpabilidad de la dictadura, que colocaba a España en una posición de gran debilidad a la hora de negociar.

Los americanos, gracias a ese tratado, han convertido Rota en una de las tres bases de submarinos (Polaris) más importantes del mundo, e instalaron bases aéreas en Zaragoza, Morón y Torrejón. A cambio de ello, fundamentalmente, proporcionaron ayuda militar en un total de 650 millones de dólares hasta 1974 (incluido), pero dentro de esta cifra contabilizaron 317 millones, invertidos en la instalación de sus propias casas. El resto fue pagado en armamento y material sobrante de la guerra de Corea, que fue cedido a nuestras Fuerzas Armadas. En general, era armamento usado y costoso de mantener.

Ciertamente, el total de la ayuda americana alcanzó cifras superiores; concretamente, 2.200 millones de dólares en la fecha antes citada (1974), pero la diferencia (entre los 650 millones pagados y los 2.200 totales) fue en concepto de material prestado, alquilado o comprado con el dinero del crédito concedido por el ExportImport Bank, pero que luego había que devolver. $\mathrm{Y}$ así, gracias al crédito, el citado año 1974 España fue el sexto comprador de armas a Estados Unidos.

En la actualidad sigue el mismo sistema: en 1976, la ayuda total concedida ascendió a 86 millones de dólares, pero sólo 15 fueron pagados en material. El resto fue para servicios, préstamos, créditos, instalaciones, etc.

Por último, señalemos que este pacto, además de ser ventajoso económicamente (pues los 15 millones de dólares son una cifra insignificante comparados con los 320 millones de pesetas de nuestro presupuesto militar), ha significado una merma en nuestra independencia militar, no ya por el hecho de tener bases extranjeras dentro, sino fundamentalmente porque nuestros ejércitos han quedado hipotecados al Ejército americano, del que dependen, a efectos de mantenimiento, desde nuestras fragatas a nuestros reactores Phantom, pasando por nuestros misiles, etc.

Concretamente, a cambio de cederles las bases, los americanos entregaban material y concedían un crédito. Del material que debían entregar descontaban el precio de la instalación de sus propias bases, y el resto lo pagaban en un material usado que para ellos era de desecho. El crédito sólo será válido para poderles comprar a ellos mismos, y luego había que devolverlo. Además, lo mismo el material cedido que el pagado debía ser mantenido, y a unos costes elevados, por los americanos. 
Desechada la inclusión de España en bloques militares, la alternativa lógica es no alineación; otra cuestión es que lo lógico sea lo conveniente o factible, y que de momento puede implicar riesgos de desestabilización la ruptura del Pacto de Mutua Defensa con Estados Unidos y, por tanto, convenga mantenerlo, aunque no guste ideológicamente y sea ruinoso económicamente hasta ahora. Por tanto, en el supuesto caso de una revisión, se deberían modificar las cláusulas en el sentido igualatorio en lo militar y justo en lo económico, exigiendo, además, el cumplimiento de las condiciones pactadas y la retirada de los Polaris de Rota.

Si del análisis a corto plazo se pasa a hacer un análisis a medio plazo se observa que actualmente se está produciendo un proceso de integración económica y política en Europa, en el que los socialistas deseamos que participe nuestro país. Cuando esto ocurra y cuando estos lazos se fortalezcan apareciendo una comunidad supranacional europea, es lógico pensar que también se producirá una integración militar, y en ella, lógicamente, deberá participar España, Pero este objetivo, esta integración militar europea, que es válido a largo o medio plazo, no tiene ninguna relación con la actual OTAN, ya que la posible alianza militar europea o el futuro ejército supranacional europeo serían defensivos continentales e independientes. En resumen, tal planteamiento puede ser asumido para un medio o largo plazo, pero no en el momento presente, ya que tal alternativa, hoy por hoy, es inexistente.

Por último, al tratar del tema de la independencia militar como alternativa a la política de alianzas militares, es preciso analizar la situación de nuestra industria de armas, buques y aeronaves, ya que sería contradictorio pretender una política de no alineación teniendo toda nuestra tecnología mediatizada por el extranjero. En este sentido parece conveniente iniciar una progresiva diversificación para asegurar su continuidad, intensificando progresivamente el autoabastecimiento mediante el desarrollo y la potenciación de una industria y de una tecnología militares propias.

\section{Modelo defensivo independiente y total}

España ocupa un lugar de privilegio en la geografía occidental por encima del trópico de Cáncer. Junto a ello, la distribución de fuerzas políticas y militares en la zona que, lejos de haber llegado a una estabilización, proporciona un mapa de cargo de interacciones, tensiones y amenazas; hacen que la Península Ibérica sea punto intermedio, puente atlántico hacia Europa, Oriente Medio y Africa, base potencial de contraataque hacia el norte de Europa, vigía avanzado europeo en este Continente en ebullición y disputa que es Africa, y lugar idóneo para controlar el paso entre dos mares altamente militarizados como son el Atlántico y el Mediterráneo. La confluencia de todos los factores citados anteriormente convierten a España en un país al que cualquiera de los dos bloques militares existentes en la zona, la OTAN y el Pacto de Varsovia, quisieran ver decantado a su lado.

España, por su realidad sociopolítica, su contexto económico y su situación geográfica se siente ligada a la Comunidad Europea occidental de naciones y unida con mayores lazos culturales a los países sureños de ella.

Es preciso un análisis político profundo para encajar el futuro lugar de España en el tablero estratégico internacional, haciendo intervenir muchos otros factores que perfilarán nuestra Defensa. Tales son: la crisis actual de los bloques militares y la necesidad de dar una proyección a la España democrática en el Mediterráneo, en América Latina y Africa.

E1 PSOE no puede ignorar la situación estratégica del Archipiélago Canario y los problemas que la cercanía del Continente africano podría conllevarle, en el caso probable de que algunos bloques militares, bien directamente o a través del Esta- 
do español, decidieran la creación de zonas fuertemente militarizadas, con capacidad ofensiva en Canarias.

Tenemos, por tanto, un acuerdo muy simple: España está en Occidente. En el Atlántico Norte están uno frente al otro, dos bloques militares: la OTAN y el Pacto de Varsovia. España posee una situación geográfica que la hace muy valiosa estratégicamente. Los dos bloques, por distintas razones y de diferente forma, desean utilizar nuestra situación. Junto a esto España debe hacer su política exterior lo más amplia, proyectiva e independiente posible. Es lo mejor para nuestros intereses nacionales. Si España se decanta de lleno hacia el bloque atlántico, se romperá el actual equilibrio y colaboraremos a aumentar la tensión en la zona, o de rechazo en otras zonas del mundo. Debemos, obviamente mantener un status político de ligadura a Occidente pero, individualmente, al margen de la política defensiva conjunta que practica.

Todo lo expuesto aconseja por parte de España una actitud de equilibrio frente a la dialéctica de bloques en pro del mantenimiento de la actual filosofía europea de seguridad, y en beneficio de una mayor capacidad de maniobra diplomática española en el mundo.

En el contexto de la no alineación con los bloques militares no cabe otro modelo militar que el llamado de «defensa independiente y total». «Independiente» porque ha de suponer la ruptura de la dependencia unidireccional en materia de objetivos estratégicos y tácticos, ruptura de la dependencia en materia de doctrina, mantenimiento de la independencia en aspectos de mando $\mathrm{y}$, sobre todo, ruptura de la independencia en lo que respecta al aprovisionamiento de material de guerra. Todo ello supone la fijación de una serie de objetivos estratégicos exclusivamente enfocados a la defensa de nuestra soberanía e independencia, valorando los riesgos y amenazas que puedan afectar directamente a España en virtud de potenciales tensiones en nuestra zona de influencia. La no alineación y el mantenimiento de un equilibrio político y diplomático con los bloques, debe excluir en un principio a España de la amenaza derivada de las posiciones enfrentadas entre ellos, lo que no implica que se mantenga una vigilancia ante esa amenaza.

En el modelo independiente que proponemos, es esencial la independencia de doctrinas y de mando. Preconizamos que estos aspectos, tan importantes en la condición de la defensa, deben ser genuinamente españoles.

En nuestro modelo, la defensa nacional ha de ser total. Total porque no hay defensa efectiva si no se encuentra involucrado todo el pueblo y toda la maquinaria económica de la sociedad en ella. Para que esto ocurra, la defensa ha de ser aceptada por el pueblo, ha de ser popular. Y para que sea popular, es preciso se encamine hacia la protección de la independencia, de la soberanía nacional, de la integridad territorial y del ordenamiento constitucional que el propio pueblo ha creado.

$\mathrm{El}$ aspecto «total» del modelo defensivo debe materializarse en el terreno práctico, en la capacidad de poder poner en pie de guerra a todo el país, a sus hombres y mujeres, a sus recursos, a su industria, a su agricultura, a sus servicios, y ante todo a su maquinaria guetrera en presencia y en potencia, dentro del más breve espacio de tiempo.

Una defensa independiente y total debe ser dirigida en primera instancia por el poder civil emanado del pueblo soberano. Por ello, el PSOE propugna la separación entre la dirección política de la Defensa y la cadena de mando militar, la supeditación de ésta a aquélla y la compenetración profunda entre ambas.

Dentro del terreno organizativo, la defensa debe estructurarse en base a que sea altamente eficaz y operativa y cumpla con los objetivos estratégicos fijados democráticamente. Todo ello no es compatible con una organización marcadamente 
territorial de las FAS, y menos si ésta lleva implicaciones políticas que en una democracia son de competencia exclusivamente civil. Es por ello, por lo que el PSOE aboga porque las FAS organicen la cadena de mando de los ejércitos de forma operativa hasta los escalones más elevados. El aspecto territorial debe relegarse únicamente a poder cubrir las necesidades burocráticas, las de reclutamiento, las de movilización y las de algún tipo de servicios especiales. No parece conveniente, por tanto, la existencia de la actual organización en capitanías generales o similares y en gobiernos militares provinciales.

Organizar la defensa es organizar la coordinación de varios ministerios, por lo que deberá profundizarse en el escalón práctico, con arreglo a la legislación actual sobre los órganos superiores de la defensa, para que dicha coordinación sea efectiva. Es preciso elaborar una ley de movilización general, donde, con criterios actuales, se describa cómo poner el país en pie de guerra y cómo se ha de conducir la actividad nacional durante la guerra.

Es necesario también elaborar una ley de reclutamiento y servicio militar que recoja el pensamiento de nuestros días sobre ese deber y derecho a la vez que es para los españoles contribuir a la defensa de España.

No puede organizarse una defensa nacional efectiva si no se dota al país de una profunda y amplia instrumentación organizativa de la defensa civil. La protección del personal no combatiente, del patrimonio nacional, de haciendas y pertenencias del pueblo, debe materializarse en una ley de defensa civil para nuestros días.

Organizar la defensa nacional es disponer de unas FAS bien organizadas y donde el dinero que se destine a ellas sea bien empleado y administrado. Alguien ha dicho que las FAS necesitan un cierto enfoque empresarial a la hora de estructurarlas de cara al empleo del presupuesto. Es cierto. Las FAS actuales tienen muchos centros de coste inútiles. Es preciso fusionar muchos servicios e instalaciones, suprimir otras, y transferir a la Administración civil algunas. Al clasificar y pasar por el cedazo lo inútil o inservible, lo no operativo e innecesario, conseguiríamos con el mismo presupuesto mayores cotas en su rendimiento. Aspectos como los citados, aspectos de organigrama más operacional que territorial, aspectos de funcionamiento, aspectos marco en cuanto a política militar y aspectos de inserción de los militares profesionales en los esquemas de la sociedad civil, son, entre otros, los que ha de recoger la Ley Orgánica de las FAS propondrá una alternativa que materialice la fusión de las FAS y el pueblo, junto a la pretensión de que adquieran una estructura más ágil, más actual y más eficaz operativamente.

Dentro del ámbito de la organización de la defensa no puede obviarse el replanteamiento de la justicia militar dentro del espíritu constitucional de la unidad de jurisdicción, y dentro de la reforma de la organización de las FAS. El PSOE propugnará la elaboración de un nuevo Código de Justicia Militar adaptado a las nuevas concepciones legales, jurídicas y procesales que se deduzcan del reacondicionamiento de la organización militar y de la actual concepción del Estado. Entretanto, el PSOE mantendrá los principios que ha esgrimido en pro de la reforma del actual código.

\section{Politica militar: integración del pueblo y las FAS}

Un modelo tal como es el que defendemos los socialistas, no puede contemplar por un lado a la sociedad y por otro a las FAS. Consideramos que las FAS, en la paz, son parte de la sociedad, y en momento de guerra, puede ser toda ella. Por tanto, es imprescindible que entre la sociedad y las FAS haya una ósmosis, una compenetración, un entendimiento y un acoplamiento perfectos. En paz, las FAS son una escuela de soldados y preparación y educación de todos los planos de la vida so- 
cial para la guerra, por lo que cada miembro de las FAS debe sentirse, dentro de la sociedad, uno más del pueblo. En guerra, sociedad y FAS se funden en un bloque con el fin de defender el patrimonio del pueblo, por lo que cada componente del pueblo debe sentirse militar. En la paz y en la guerra, FAS y pueblo han de ser solidarios para que puedan cumplirse todos los objetivos previstos, que han de ser comunes al sentir de ambos como pertenecientes a la misma sociedad inspirada en las directrices emanadas del Parlamento y del Gobierno.

La consecución de una ósmosis real entre la sociedad y las FAS, y viceversa, debe pasar por la asunción de la Constitución por parte de la instrucción militar como conjunto de principios supremos propios. De igual forma, el pueblo ha de ver en el estamento militar el encargado de llevar a la práctica la alta misión de servir de eje en la Defensa Nacional. Mediante la puesta en práctica de este modelo de Defensa, que entraña la reforma de la enseñanza militar en todos sus niveles y la reforma manteniendo el servicio militar obligatorio. El PSOE cree que puede asegurarse y afianzarse un acoplamiento mutuo entre la sociedad y las FÄS.

Para concretar estos objetivos se deben tomar las medidas siguientes:

1. Simplificar al máximo los mecanismos de reclutamiento y movilización, haciendo que el soldado realice un servicio militar, en la medida que sea posible, en la región militar de origen, para lo que basta abolir un decreto de fines del 75 , en virtud del cual se sustituye el tradicional sistema de reclutamiento llamado de «base nacional», que consiste en que los reclutas hagan el servicio militar en un lugar alejado de su pueblo natal, con el consiguiente coste económico para el Estado y afectivo para la familia del soldado.

2. Adaptar el Código de Justicia Militar al nuevo orden constitucional y democrático, cumpliendo lo antes posible lo establecido en el Título VII de la segunda parte de los acuerdos de la Moncloa, según los cuales, «se reconsiderarán los límites de la competencia de la jurisdicción militar» restringiéndolos por razón de delito (casos de dualidad de tipificaciones), de lugar (limitándolo a los estrictamente militares) y de la persona (concurrencia de personal no militar), así como desaforando a las Fuerzas de Orden Público, incluso «cuando actúen en el mantenimiento del mismo».

3. Agilizar la forma de realizar el servicio militar, adaptándolo a las necesidades de las ciudades, tal como se hace actualmente en algunos países de Europa.

4. Dar un cumplimiento real y generoso a la Ley de Amnistía aprobada por las Cortes. Real por cuanto, pese al tiempo pasado, muchos de los antiguos militares republicanos siguen sin cobrar los devengos que la citada ley les reconoce y generoso por cuanto consideramos que en su espíritu debería entrar el resolver el problema de una veintena escasa de militares que perdieron la carrera por luchar contra la dictadura, y tienen aún edad para reingresar en el servicio activo.

5. Ofrecer a los miembros de las Fuerzas Armadas, y especialmente a los cuadros, posibilidades reales de conocer la Constitución, introduciendo en las revistas militares las modificaciones que convenga y haciendo las necesarias reformas en los planes de estudio de las academias militares (de oficiales y suboficiales), en las cuales se debería introducir el estudio del Derecho constitucional y las convenientes asignaturas de humanidades, adecuando la organización de la enseñanza militar a las necesidades de la nueva etapa democrática, y también a la metodología y pedagogía del tiempo presente, conforme a las resoluciones del XXVII Congreso, que establecen que «no se puede hablar de una formación integral de los militares si no se estudia en profundidad, además de una tecnología bélica, al pueblo, que en un momento dado, se tiene que encuadrar para la defensa».

6. Completar la integración de los tres Ejércitos en un Ministerio de Defensa 
único, coordinando unas actividades (como la enseñanza y la fabricación y compra de armas y medios) y unificando otras (como los servicios de sanidad, farmacia, intervención, jurídico, etc.), lo que implicaría la lógica economía de hombres, medios y gastos.

Como consecuencia de la citada unificación de actividades y servicios debería reestructurarse el Ministerio de Defensa, aumentándose las atribuciones al ministro y subsecretario, del que deberían pasar a depender todas las funciones políticas, económicas o administrativas a través de direcciones generales (personal, armamento y material de servicios, enseñanza, etc.) que deberían ser desempeñadas por personas elegidas libremente por el ministro, con los mismos criterios que en los restantes Ministerios, y por tanto, bajo el control del Parlamento.

7. Realizar una política de personal adecuada para todos los miembros de las FAS, prestando especial atención a los derechos civiles del militar y a los sectores no centrales de la organización, como los especialistas, funcionarios civiles al servicio de la Administración militar, trabajadores de bases y talleres, de fábricas militares, los cuales tienen todavía limitados sus derechos civiles por razón de su trabajo militar.

Como consecuencia con todo lo expuesto en política de Defensa y en política Militar, se proponen los siguientes ACUERDOS:

1. No entrar en ningún bloque militar.

2. Luchar por la paz apoyando el desarme y la desmilitarización en los tres sentidos: primero, insistiendo en la necesidad de disminuir los gastos bélicos de todos los países, y por tanto, también del nuestro; segundo, potenciando toda política de prohibición de las armas más mortíferas (como la bomba de neutrones, etc.), o de limitación mutua de armas (como en las conversaciones Salt-2), y tercero, potenciando la desmilitarización de un máximo de espacios como se hace en las conversaciones MBFR, para el desarme en el centro de Europa, tendiendo a crear una política semejante en el área mediterránea.

3. Oponerse al establecimiento de instalaciones militares extranjeras o de organizaciones supranacionales en Canarias, así como a la utilización de las bases nacionales allí existentes por otras potencias, entendiendo que la conveniencia de una adecuada defensa de Canarias habrá de corresponderse con la naturaleza local de los presuntos agresores y no debe alcanzar cotas de estrategia continental o mundial.

4. Fomentar el desarrollo de una industria militar propia que permita reducir las importaciones de armas extranjeras, y simultáneamente impedir que nuestro país siga siendo intermediario para la venta de armas a países de régimen dictatorial, y en los que no se respeta a la producción, sino también toda empresa que se dedique al tráfico de armas. Tomar medidas legislativas y judiciales para abortar de una vez el citado tráfico.

5. Presentar, por nuestro grupo parlamentario, tres proposiciones de ley, una para que se haga el servicio militar en la región de origen, otra para que se amplíe la amnistía militar a los que quedaron excluidos de la anterior ley; una tercera para reestructurar el Ministerio de Defensa. Además deberá defender nuestro grupo parlamentario las 89 enmiendas que en la anterior legislatura se presentaron al Proyecto de Ley del Gobierno, sobre la reforma del Código de Justicia Militar, dada la debilidad de este proyecto.

6. Insistir para que se realicen las transformaciones necesarias y convenientes dentro de las Fuerzas Armadas, a fin de lograr su máxima identificación con el orden democrático y la Constitución. 
7. Tender un máximo de puentes con los mandos de las Fuerzas Armadas, a fin de lograr la creación de un clima cordial entre éstas y el Partido, para lo cual es premisa previa un adecuado conocimiento. En los lugares en que existen parlamentarios (diputados o senadores) de la Comisión de Defensa, deberán ser éstos los que realicen las citadas relaciones, dándoles un carácter público y oficial siempre que sea posible.

8. Todo afiliado del PSOE, a cualquier nivel, procurará mantener las buenas relaciones con los militares que conozca, y los compañeros que hagan el servicio militar se esforzarán en ser soldados ejemplares, persuadidos de que el prestigio personal que adquieran, será en buena medida utilizado por sus mandos para juzgar al Partido Socialista. 